and an unrecordable blood pressure. A second central venous catheter was therefore inserted exclusively for infusion of dopamine. Four days after her admission the infusion was successfully stopped. She was eventually discharged from hospital having made a complete recovery.

\section{Discussion}

This patient had streptococcal cellulitis that caused circulatory and respiratory failure masquerading as venous thrombosis and pulmonary embolism. Streptococcal infection may be rapidly progressive and fatal despite treatment with antibiotics, and seven out of eight patients reported on recently died.' ' In our patient antibiotics would not have influenced the outcome without early intensive supportive measures, including full haemodynamic monitoring. In particular, we were impressed by the extreme dependence of her condition on dopamine.

The existence of a factor that acts as a myocardial depressant and contributes to shock in cases of severe sepsis has previously been postulated. ${ }^{34}$ Although thermodilution studies to measure cardiac output were not performed in this patient, we believe that the rapidity of onset and degree of hypotension together with the bradycardia that occurred when the dopamine infusion was interrupted strongly suggest the presence of such a humoral factor in our case.

\section{References}

1 Goepel JR, Richards DG, Harris DM, Henry L. Fulminant streptococcus pyogenes infection. $\mathrm{Br}$ Med $\mathcal{F} 1980 ; 281: 1412$.

${ }^{2}$ Cruickshank JG, Hart RJC, George M, Feest TG. Fatal streptococcal septicaemia. Br Med f $1981 ; 282: 1944-5$.

${ }^{3}$ Lovett WL, Wangensteen SL, Glenn TM, Lefer AM. Presence of a myocardial depressant factor in patients in circulatory shock. Surgery $1971 ; 70: 223-31$.

${ }^{4}$ Lefer AM. Blood-borne humoral factors in the pathophysiology of circulatory shock. Circ Res 1973;32:129-39.

(Accepted 9 December 1983)

\title{
Effect of prenalterol on orthostatic hypotension in the Shy-Drager syndrome
}

\begin{abstract}
Treatment of idiopathic orthostatic hypotension is often unsatisfactory. A patient with the Shy-Drager syndrome, in which the most important symptom is orthostatic hypotension, was treated with prenalterol, initially $30 \mathrm{mg}$ six times daily. The dosage was reduced to $30 \mathrm{mg}$ four times daily because of the development of complex ventricular premature beats. Orthostatic symptoms were reduced and standing blood pressure increased. Fludrocortisone $0.5 \mathrm{mg}$ a day was added to treatment with further improvement. This clinical effect was maintained throughout 12 months of follow up, during which the treatment was continued unchanged.

Prenalterol was effective in reducing orthostatic symptoms in this patient. Further studies in patients with a similar haemodynamic pattern are indicated.

\section{Introduction}

Idiopathic orthostatic hypotension may occur either as an isolated disorder or in association with multiple defects of the central nervous system when it is known as the Shy-Drager syndrome. Treatment of this disabling condition is often unsatisfactory.' We report the effects of prenalterol, a selective $\beta_{1}$ adrenoceptor agonist, ${ }^{2}$ in a patient with the Shy-Drager syndrome.

Department of Internal Medicine, University of Leuven, Leuven, Belgium

J GOOVAERTS, MD, clinical assistant

C VERFAILLIE, MD, clinical assistant

R FAGARD, MD, lecturer in cardiology

D KNOCKAERT, MD, adjunct head of clinic

Correspondence to: Dr J Goovaerts, University Hospital Gasthuisberg, Service of Internal Medicine, University of L,euven, B-3000 Leuven, Belgium.
\end{abstract}

\section{Case report}

A 50 year old man was admitted to hospital because of an attack of syncope. He had suffered from dizziness, fainting, and stiffness of the legs for several months. For two years he had complained of urinary frequency, nocturia, urge incontinence, loss of potency, diarrhoea, faecal incontinence, and diminished sweating. On admission his supine blood pressure was $115 / 69 \mathrm{~mm} \mathrm{Hg}$ and heart rate 64 beats $/ \mathrm{min}$. When he stood up his blood pressure immediately fell to $66 / 24 \mathrm{~mm} \mathrm{Hg}$ and his heart rate increased to 92 beats/minute. Despite a partial recovery of blood pressure after one minute $(94 / 52 \mathrm{~mm} \mathrm{Hg})$ he could not walk because of dizziness and blurring of vision.

A thorough investigation excluded secondary forms of orthostatic hypotension. The Shy-Drager syndrome was diagnosed because of the association of features of autonomic failure with clinical signs that the central nervous system was affected (pyramidal, cerebellar, vestibular, and sensory signs); an abnormal blood pressure response to the Valsalva manoeuvre; a normal baseline plasma noradrenaline concentration $(0.384 \mu \mathrm{g} / \mathrm{l})$ with an inadequate increase on standing $\left(+46{ }^{\circ}\right)$; and mild supersensitivity to noradrenaline and tyramine. According to Bannister et al supersensitivity to noradrenaline is defined as a rise in systolic blood pressure of $>15 \mathrm{~mm} \mathrm{Hg}$ in response to an infusion of noradrenaline $<4 \mu \mathrm{g} /$ minute. $^{3}$ An equal response to a tyramine infusion of $<300 \mu \mathrm{g} /$ minute indicates supersensitivity to tyramine. In our patient systolic blood pressure increased by $16 \mathrm{~mm} \mathrm{Hg}$ during infusion of $1 / \mathrm{kg}$ noradrenaline/minute and by $19 \mathrm{~mm} \mathrm{Hg}$ during infusion of $250 \mu \mathrm{g}$ tyramine/minute. Brachial artery catheterisation (Vygon, 115.09) and flow directed right heart catheterisation with a Swan-Ganz catheter were performed. Cardiac output was calculated according to the Fick principle (cardiac output - oxygen consumption: arteriovenous oxygen difference). Systemic vascular resistance was calculated from the mean brachial intra-arterial pressure, obtained by electrical damping, and cardiac output. Stroke volume was calculated from cardiac output and heart rate. Heart rate was recorded from the electrocardiogram. Haemodynamic data obtained before treatment indicated that orthostatic hypotension was related to a dramatic fall in stroke volume with inadequate cardiac output despite the increase in heart rate (table).

Treatment with a $150 \mathrm{mmol}(\mathrm{mEq})$ sodium diet and fludrocortisone in increasing dosage up to $1.0 \mathrm{mg} /$ day resulted in symptomatic im- 
Blood pressure, heart rate, and echocardiographic and haemodynamic data before and during treatment with prenalterol and fludrocortisone

\begin{tabular}{|c|c|c|c|}
\hline & $\begin{array}{c}\text { Before } \\
\text { treatment }\end{array}$ & $\begin{array}{c}\text { Prenalterol } \\
4 \times 30 \mathrm{mg} / \text { day }\end{array}$ & $\begin{array}{c}\text { Prenalterol } \\
4 \times 30 \mathrm{mg} / \text { day }+ \\
\text { fludrocortisone } \\
0.5 \mathrm{mg} / \text { day }\end{array}$ \\
\hline $\begin{array}{l}\text { Blood pressure }(\mathrm{mm} \mathrm{Hg}) \text { : } \\
\text { Supine } \\
\text { Immediately on standing upright } \\
\text { After standing for } 10 \text { minutes }\end{array}$ & $\begin{array}{r}104 / 68 \\
72 / 42 \\
88 / 68\end{array}$ & $\begin{array}{l}124 / 72 \\
102 / 58 \\
110 / 82\end{array}$ & $\begin{array}{l}144 / 74 \\
118 / 80 \\
126 / 88\end{array}$ \\
\hline $\begin{array}{l}\text { Heart rate (beats/min): } \\
\text { Supine } \\
\text { Immediately on standing upright } \\
\text { After standing for } 10 \text { minutes }\end{array}$ & $\begin{array}{l}68 \\
86 \\
76\end{array}$ & $\begin{array}{l}88 \\
99 \\
98\end{array}$ & $\begin{array}{r}80 \\
104 \\
88\end{array}$ \\
\hline $\begin{array}{l}\text { End diastolic left ventricular } \\
\text { internal diameter (LVID) }\end{array}$ & \multicolumn{2}{|c|}{ Echocardiographic data } & \\
\hline $\begin{array}{l}\text { (supine) (mm) } \\
\text { Fractional shortening of LVID }\left({ }_{0}^{\circ}\right) \\
\text { Left ventricular end systolic stress }\end{array}$ & $\begin{array}{l}47 \\
27\end{array}$ & $45^{*}$ & $\begin{array}{l}57 \\
39\end{array}$ \\
\hline$(\mathrm{mm} \mathrm{Hg})$ & $55 \cdot 7$ & $43 \cdot 6^{*}$ & $78 \cdot 6$ \\
\hline \multicolumn{4}{|c|}{ Haemodynamic data } \\
\hline $\begin{array}{l}\text { Mean arterial pressure }(\mathrm{mm} \mathrm{Hg}) \text { : } \\
\text { Supine } \\
\text { Standing }\end{array}$ & $\begin{array}{l}80 \\
64\end{array}$ & & $\begin{array}{l}87 \\
70\end{array}$ \\
\hline $\begin{array}{l}\text { Cardiac output }(1 / \mathrm{min}) \text { : } \\
\text { Supine } \\
\text { Standing }\end{array}$ & $\begin{array}{l}4 \cdot 76 \\
2 \cdot 68\end{array}$ & & $\begin{array}{l}5 \cdot 14 \\
3 \cdot 64\end{array}$ \\
\hline $\begin{array}{l}\text { Systemic vascular resistance } \\
(\mathrm{mm} \mathrm{Hg} / \mathrm{l} / \mathrm{min}):\end{array}$ & & & \\
\hline $\begin{array}{l}\text { Supine } \\
\text { Standing }\end{array}$ & $\begin{array}{l}16 \cdot 8 \\
23 \cdot 9\end{array}$ & & $\begin{array}{l}16 \cdot 9 \\
19 \cdot 2\end{array}$ \\
\hline $\begin{array}{l}\text { Stroke volume (ml/beat): } \\
\text { Supine } \\
\text { Standing }\end{array}$ & $\begin{array}{l}78 \\
32\end{array}$ & & $\begin{array}{l}75 \\
35\end{array}$ \\
\hline $\begin{array}{l}\text { Pulmonary capillary wedge } \\
\text { pressure }(\mathrm{mm} \mathrm{Hg}):\end{array}$ & & & \\
\hline $\begin{array}{l}\text { Supine } \\
\text { Standing }\end{array}$ & $\begin{array}{l}6 \\
0\end{array}$ & & $7 \cdot 5$ \\
\hline
\end{tabular}

*Data obtained one hour after a single dose of prenalterol $30 \mathrm{mg}$ by mouth.

provement. After two weeks, however, fludrocortisone treatment had to be interrupted because of congestive heart failure. Treatment with prenalterol $30 \mathrm{mg}$ six times daily was started one week later. This dose was subsequently reduced to $30 \mathrm{mg}$ four times daily because of complex ventricular premature beats seen on 24 hour electrocardiography (multiform ventricular premature beats, couplets, and short runs of ventricular tachycardia with a maximum of 12 consecutive beats and a highest rate of 125 beats $/ \mathrm{min}$ ). A control electrocardiogram obtained after reduction of the dose showed occasional isolated ventricular premature beats; these had been present before treatment.

With a regimen of prenalterol $30 \mathrm{mg}$ four times a day he was able to stand and walk for one hour without major complaints. In addition, he noticed a considerable improvement in bowel frequency and frequency of micturition. After two weeks, fludrocortisone $0.5 \mathrm{mg} /$ day was added to prenalterol, resulting in further symptomatic improvement. These favourable results were confirmed by blood pressure measurements in the supine and standing positions (table). Haemodynamic investigation (table) showed a substantial increase in cardiac output in the upright position, mainly due to an increase in heart rate. Echocardiography showed an increase in fractional shortening of the left ventricular internal diameter with prenalterol, while fludrocortisone enlarged the diameter. The combination of the drugs clearly increased end systolic left ventricular meridional wall stress, calculated as suggested by Reichek et al. ${ }^{4}$ The clinical effect lasted during the ensuing 12 months without change of treatment.

\section{Discussion}

Existing treatment schedules for neurogenic orthostatic hypotension have their limitations. ${ }^{1}$ Therapeutic measures aimed at increasing the heart rate and enhancing myocardial contractility have been tried with variable success in the past few years. Atrial pacing at 100 beats/minute produced considerable symptomatic and haemodynamic improvement in a patient with intractable idiopathic orthostatic hypotension. ${ }^{5}$ Pindolol, a partial $\beta$ adrenoceptor agonist, exerted positive chronotropic and inotropic effects in patients with orthostatic hypotension due to peripheral autonomic neuropathy and resulted in substantial symptomatic improvement. ${ }^{6}$ In contrast, pindolol has had deleterious effects in patients with the Shy-Drager syndrome, in whom the drug acts as a $\beta$ adrenoceptor antagonist. ${ }^{7}$ Pren- alterol, a selective $\beta_{1}$ adrenoceptor agonist," appeared to be effective in our patient with Shy-Drager syndrome.

The main aim of giving prenalterol in this case was to enhance myocardial contractility because the orthostatic hypotension was related to a large fall in stroke volume and cardiac output while peripheral resistance was adequate. Prenalterol $30 \mathrm{mg}$ four times a day produced a satisfying reduction in orthostatic symptoms and a considerable increase in standing blood pressure. Addition of fludrocortisone $0.5 \mathrm{mg}$ /day further increased supine and standing blood pressures without causing supine hypertension. The main haemodynamic effect of treatment with prenalterol and fludrocortisone was an appreciable increase in standing cardiac output, primarily due to an increase in heart rate without much change in stroke volume. The unchanged stroke volume during combined treatment, despite the positive inotropic effect of prenalterol and the increased preload, as evidenced by echocardiography, may be explained by the considerably enhanced end systolic left ventricular meridional wall stress, a measurement of myocardial afterload. According to these data, the chronotropic effect of prenalterol was the most important factor contributing to the haemodynamic improvement. The occurrence of complex ventricular premature beats at the start of treatment was probably due to overdosage of the drug.

Because of the effectiveness of prenalterol in this patient with the Shy-Drager syndrome further studies should be carried out in patients with the same haemodynamic pattern. The occurrence of cardiac arrhythmias, however, may be a drawback to the use of $\beta$ adrenoceptor agonists in patients with autonomic failure. Careful dose adjustments are mandatory as the degree of denervation supersensitivity determines the response to sympathomimetic agents. ${ }^{3}$

\section{References}

${ }^{1}$ Schatz IJ. Current management concepts in orthostatic hypotension. Arch Int Med 1980;140:1151-4.

2 Ablad B, Hjalmarson $\AA$, Johnsson G. Pharmacological and clinical effects of prenalterol-a new inotropic beta-adrenoceptor stimulant. Proceedings of the symposium in Hamburg, December 5, 1980. Acta Med Scand 1982;suppl 659:1-325.

${ }^{3}$ Bannister R, Davies B, Holly E, Rosenthal T, Sever P. Defective cardiovascular reflexes and supersensitivity to sympathomimetic drugs in autonomic failure. Brain 1979;102:163-76.

${ }^{4}$ Reichek N, Wilson J, Sutton M, Plappert TA, Goldberg G, Hirshfeld $J W$. Non-invasive determination of left ventricular end-systolic stress, validation of the method and initial application. Circulation 1982;65: 99-108.

${ }^{5}$ Moss AJ, Glasser W, Topol E. Atrial tachypacing in the treatment of a patient with primary orthostatic hypotension. N Engl f Med 1980; 302:1456-7.

${ }^{6}$ Man in 't Veld AJ, Schalekamp MADH. Pindolol acts as beta-adrenoceptor agonist in orthostatic hypotension: therapeutic implications. $\mathrm{Br} \mathrm{Med} \mathcal{F}$ $1981 ; 282: 929-31$.

${ }^{2}$ Davies B, Bannister R, Mathias C, Sever P. Pindolol in postural hypotension, the case for caution. Lancet 1981 ;i : $982-3$.

(Accepted 10 fanuary 1984)

ONE HUNDRED YEARS AGO Last week there was inaugurated a movement by leading students of Edinburgh University, which, if successfully carried out, will be of much benefit to students and to the university. Hitherto there has been no cohesion in the vast body of young men who constitute the most important feature of Scottish university success. The only occasions on which there was any approach to concerted action of any considerable bodies of students were during rectorial elections, and hitherto that has been almost exclusively on diverging political lines. Now, however, it is proposed to have elected by all the faculties a representative council for students. This council will be able to express the wishes of the students, their opinions on various intramural matters, and will be a means of amicable intercourse with the Senatus Academicus. By the last named body we believe the movement is looked on very favourably. (British Medical fournal 1884 ; : 185.) 